\title{
MECHANICAL BEHAVIOR AND DAMAGE PROCESSES OF UDIMET 720Li: INFLUENCE OF LOCALIZED PLASTICITY AT GRAIN BOUDARIES
}

\author{
Patrick VILLECHAISE ${ }^{1}$, Jonathan CORMIER ${ }^{1}$, Thomas BILLOT ${ }^{1,2}$, José MENDEZ ${ }^{1}$ \\ ${ }^{1}$ Institut Pprime - UPR CNRS 3346; Ecole Nationale Supérieure de Mécanique et d'Aérotechnique (ENSMA) \\ 1 Avenue Clément Ader; BP 40109; 86960 Futuroscope Chasseneuil; France \\ ${ }^{2}$ Presently at Snecma - SAFRAN group; site de Genevilliers; YQGF Technical Division; 92702 Colombes Cedex; France
}

Keywords: Creep, Fatigue, Grain boundaries, Localized plasticity, EBSD

\begin{abstract}
The creep-fatigue properties at $700^{\circ} \mathrm{C}$ of cast and wrought Udimet $720 \mathrm{Li}$ superalloy have been investigated. As expected, the introduction of a dwell time as low as $1 \mathrm{~s}$ at maximum stress induces a creep-fatigue life debit compared to pure fatigue conditions. It is demonstrated that the mechanical behavior (plastic strain rate, ductility) is greatly affected by the grain size and precipitation distribution. Moreover, the creep-fatigue life seems to be hardly affected by the alloy microstructure, due to the development of localized damage. Whatever the environmental conditions (i.e. in air or under vacuum), failure has been identified to be intergranular.
\end{abstract}

To get a better understanding of the contribution from grain boundaries to the first stage of plasticity and damage development, in-situ tensile tests were performed in a scanning electron microscope (SEM). In a first step to get a full understanding of the role of grain boundaries in controlling the mechanical properties and alloy durability, we first paid attention to the contribution of the local grain crystallography to the plasticity heterogeneity near grain boundaries. This was performed at room temperature where, compared to creepfatigue loading at $700^{\circ} \mathrm{C}$, the role of viscoplasticity can be neglected. First evidences of slip activity were shown to depend only on the local Schmid factor and not on the grain size. In addition, these experiments were performed using samples with a homogeneous grain size and a homogeneous intragranular $\gamma^{\prime}$ particles distribution. By using the recently developed electron backscattered diffraction (EBSD) pattern cross-correlation technique, it has been shown that critical grain configurations exist, which lead to the activation of micro-volumes $\left(\sim 1-2 \mu \mathrm{m}^{3}\right.$ at maximum) where intense plastic activity develop near grain boundaries. These volumes nucleate at grain boundaries separating two grains having a slip activity contrast: they develop in the grain less favorably oriented for slip, ahead of slip bands which had developed in the grain with easier slip. It is observed that the very first stages of development of intense plasticity micro-volumes are quite insensitive to a contrast in Schmid factors between neighboring grains. The local von Mises stress magnitude in these volumes can be as large as several $\mathrm{GPa}$, sufficient enough to develop micro-cracking.

\section{Introduction}

Forged nickel-based superalloys are widely used for the design of aeroengines and land-based high pressure turbine disks. Usually, the design of such components is mainly based on low cycle fatigue (LCF) life criteria and resistance against disk burst $[1,2]$. Both of these properties are maximized using high strength alloys with a homogenous small grain size (typically
ASTM 9 or less). However, in case of high temperature disk applications $\left(\mathrm{T}>650^{\circ} \mathrm{C}\right)$, time dependent damage processes such as creep and creep-fatigue crack propagation may be encountered in the rim, requiring increased grain sizes. Udimet ${ }^{\circledR}$ $720 \mathrm{Li}$ (U720Li), a $\gamma^{\prime}$ strengthened alloy, is one of the most successful alloy for such high temperature applications. This alloy, which was developed in the late 70's [3], exhibits one of the highest temperature capability $\left(\sim 730^{\circ} \mathrm{C}\right)$ among other Nibased disk alloys [4]. For this reason, this alloy, processed using either the cast and wrought $(\mathrm{C} \& \mathrm{~W})$ or the powder metallurgy (PM) processing routes, has been chosen for a great number of industrial applications $[5,6]$, despite its sensitivity to quench cracking owing to its quite high $\gamma^{\prime}$ content $(\sim 45 \%)$ [7, 8]. During high temperature cyclic loadings, the durability of $\mathrm{C} \& \mathrm{~W} \mathrm{Ni}-$ based alloys is often controlled by the development of damage at grain boundaries [9] or near inclusions [10], those processes being oxidation assisted (i.e. surface crack initiation) or not.

Very few studies have been devoted to the understanding of the contribution of grain boundaries and local crystallography to the alloys durability $[9,11,12]$. As example, it was recently demonstrated that there is a pronounced contribution of grain boundaries to the creep deformation of NR6 superalloy [12]. However the very early stages of crack initiation as a function of the local crystalline configurations were scarcely studied for $\mathrm{Ni}$ based superalloys. Recently studies have pointed out the role of clusters of unfavorably oriented grains on crack initiation [9]. We intend in the present paper to focus on the role of grain boundaries in the first stages of micro-cracking as a function of the surrounding microstructure (i.e. grains orientations and $\gamma^{\prime}$ precipitation). This can be achieved by performing in-situ tensile tests in a SEM and using EBSD analyses. Moreover this study is an introduction to the recent cross correlation technique associated with EBSD which allows the measurement of local strain/stress fields [13].

This article will be divided in the following way: after a brief presentation of the experimental techniques and of the alloy microstructure which have been studied, the creep-fatigue behavior and damage processes of $\mathrm{U} 720 \mathrm{Li}$ at $700^{\circ} \mathrm{C}$ as a function of its microstructure (especially grain size distribution) will be presented and analyzed. In a second main part, the strain/stress distributions and first stage of crack nucleation near grain boundaries will be studied using in-situ SEM tensile testing, EBSD and the cross-correlation technique. In a first step of understanding, these experiments are performed at room temperature (i.e. avoiding time-dependent processes) using a model microstructure (i.e. homogeneous coarse grains and homogeneous monomodal intragranular $\gamma^{\prime}$ precipitation). This simple microstructure was produced so that attention could be focused on the contribution of local crystallography. 


\section{Experimental Techniques}

$\underline{\text { Material }}$

The chemical composition of U720Li is provided in Table 1. Two kinds of microstructure were studied for creep-fatigue experiments. The first one presents a homogeneous coarse grain size distribution ranging from $90 \mu \mathrm{m}$ up to $800 \mu \mathrm{m}$, with an average grain size about $350 \mu \mathrm{m}$ (Fig. 1a). The second one is heterogeneous with a bimodal distribution composed of clusters of small grains (average size $=50 \mu \mathrm{m}$, range $=[40 \mu \mathrm{m}-60$ $\mu \mathrm{m}]$ ) merged in a coarse grain skeleton (average size $=250 \mu \mathrm{m}$, range $=[125 \mu \mathrm{m}-500 \mu \mathrm{m}])$. These microstructures will be denoted in the following of the article as the "Homogeneous" and "Heterogeneous" microstructures, respectively. The Homogeneous microstructure was obtained using a supersolvus solution treatment (ST) while the Heterogeneous one was obtained with a special ST, which is proprietary to Aubert \& Duval and Turbomeca - SAFRAN group. The following aging procedure was used for both microstructures: $20 \mathrm{~h}$ at $700^{\circ} \mathrm{C} / \mathrm{Air}$ Quench (AQ) $+16 \mathrm{~h} / 815^{\circ} \mathrm{C} / \mathrm{AQ}$. Intragranular $\gamma / \gamma^{\prime}$ microstructures presented in Figs. 1d and 1e were obtained for the Homogeneous and Heterogeneous alloys, respectively. It should mentioned that the Heterogeneous microstructure presents primary $\gamma^{\prime}$ particles at grain boundaries (volume fraction $\sim 3 \%$, size $\sim 2-3 \mu \mathrm{m}$ ) located in the small grain clusters. Intragranular secondary $\gamma^{\prime}$ precipitation for both types of microstructure is typical of supersolvus ST with medium cooling rates $[14,15]$. The corresponding average sizes are $325 \mathrm{~nm}$ and $275 \mathrm{~nm}$ for the Homogeneous and Heterogeneous microstructures, respectively. Small tertiary $\gamma^{\prime}$ particles (40 - 50 $\mathrm{nm}$ ) nucleating in the last stages of the cooling from the ST

temperature [16] can also be observed for both microstructures

Table 1. U720Li nominal composition

\begin{tabular}{|c|c|c|c|c|c|c|}
\hline Element & $\mathrm{Ni}$ & $\mathrm{Cr}$ & $\mathrm{Co}$ & $\mathrm{W}$ & $\mathrm{Ti}$ & $\mathrm{Al}$ \\
\hline $\mathrm{Wt} \%$ & $\mathrm{Bal}$ & 16.2 & 14.6 & 1.2 & 4.97 & 2.51 \\
\hline Element & $\mathrm{Mo}$ & $\mathrm{C}$ & $\mathrm{B}$ & $\mathrm{Zr}$ & $\mathrm{Fe}$ & \\
\hline $\mathrm{Wt} \%$ & 2.9 & 0.014 & $<0.03$ & $<0.06$ & $<0.2$ & \\
\hline
\end{tabular}

Finally, a third "academic" microstructure was investigated for the specific purpose of in-situ SEM tensile testing and for the study of the role of grain boundaries to the development of localized plasticity and damage nucleation. This microstructure was obtained using the following heat treatment: $4 \mathrm{~h}$ at $1160^{\circ} \mathrm{C} /$ oil quench $+16 \mathrm{~h}$ at $760^{\circ} \mathrm{C} / \mathrm{AQ}+24 \mathrm{~h}$ at $650^{\circ} \mathrm{C} / \mathrm{AQ}$. It produces an alloy with a coarse grain structure (see Fig. 1c, average grain size $=456 \mu \mathrm{m}$, range $=[45 \mu \mathrm{m}-1900 \mu \mathrm{m}])$ and $\mathrm{a}$ homogenous intragranular $\gamma^{\prime}$ precipitation built with secondary (cooling) particles whose average size is $69 \mathrm{~nm}$ (Fig. 1f) and fine tertiary particles whose average size is close to $10 \mathrm{~nm}$ [17]. A very small content of primary $\gamma^{\prime}$ particles $(0.7 \%)$ remains after such a ST. This microstructure will be mentioned in the following of the article as the "HS-homogenous" microstructure since very high $0.2 \%$ yield stress (YS) are obtained with such a supersolvus heat treated alloy (YS $1090 \mathrm{MPa}$ ) [17]. Moreover this microstructure presents very little strain hardening during tensile testing [17].

The Homogeneous and Heterogeneous microstructures were obtained in disk forged and supplied by Aubert \& Duval and Turbomeca - SAFRAN group. Samples for mechanical testing were subsequently machined from these disks.
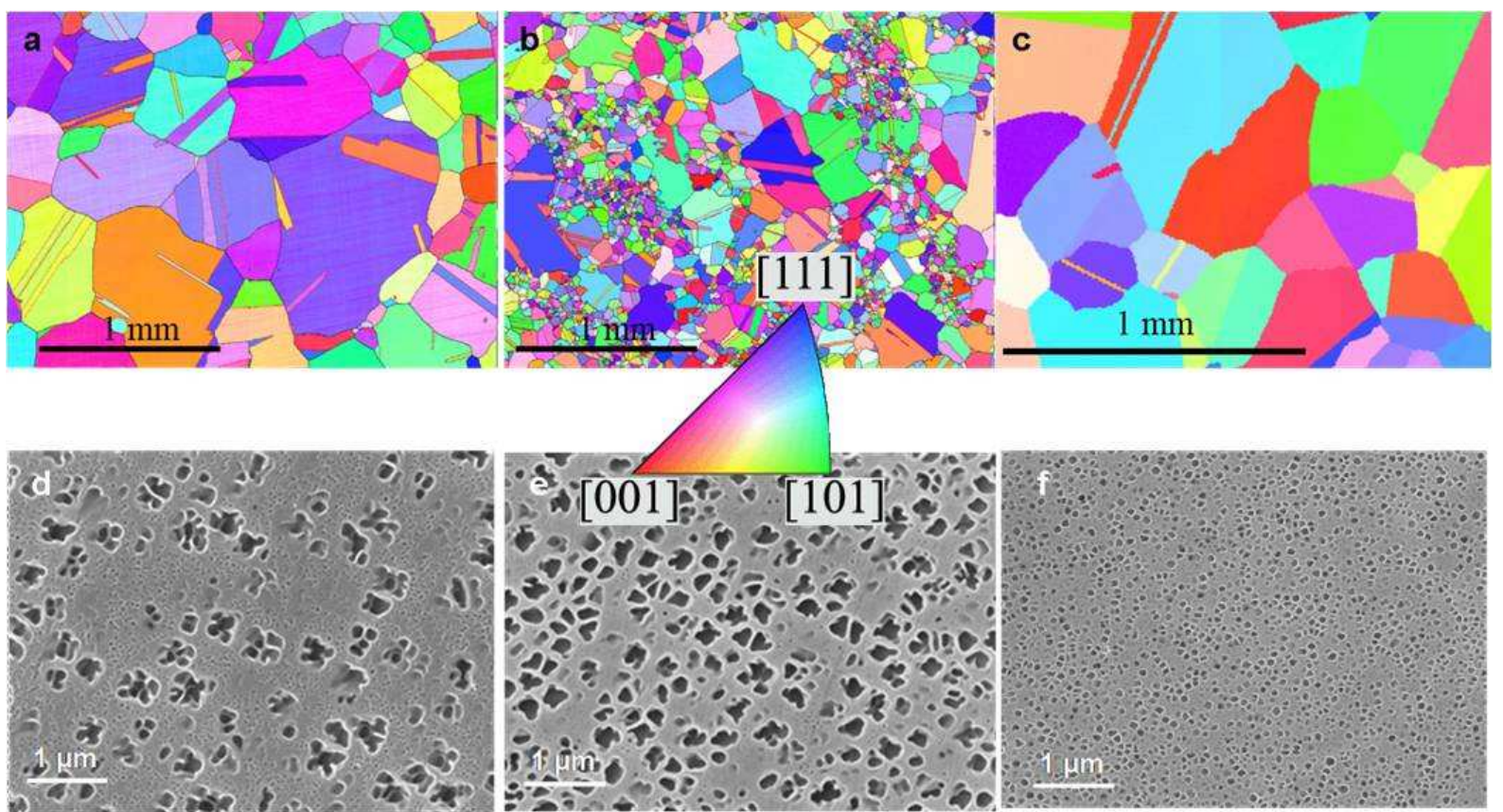

Figure 1. Representative grain microstructures obtained by EBSD (crystalline orientation coded in color according to the normal of the surface) (a-c) and corresponding $\gamma / \gamma^{\prime}$ microstructures observed after chemical etching and using the SEM secondary electron mode (d-f) for the Homogeneous microstructure (a and d), the Heterogeneous ( $b$ and e) and the HS-homogenous ( $c$ and $f$ ). 
The HS - Homogeneous microstructure was obtained at Pprime Institute by heat treating (ST treatment + agings) samples which were machined out from a $80 \mathrm{~mm}$ forged bar at mid-radius.

\section{Mechanical Testing}

Samples used for macroscopic creep-fatigue testing were machined out of the different forgings by electro-discharge machining and lathe-turning. They had a cylindrical gage section, $13 \mathrm{~mm}$ in length and $4.37 \mathrm{~mm}$ in diameter. After machining, they were automatically polished up to a $4000 \mathrm{SiC}$ paper. A final manual polishing of the gage length to a mirror finish (with a $1 \mu \mathrm{m}$ diamond spray) was performed to avoid any premature failure from surface scratches. Creep-fatigue tests were performed under pure load control, with a stress ratio $R_{\sigma}=$ 0.05 , using a trapezoidal cycle. Loading and unloading lasted 1 second while the dwell time at maximum applied stress $\left(\sigma_{\max }\right)$ was varied from 1 second up to 1000 seconds. The maximum applied stress was varied from 650 up to $800 \mathrm{MPa}$. Tests were performed using an Instron 1362 electromechanical fatigue machine equipped with a radiant furnace. Experiments were performed at $700^{\circ} \mathrm{C}$ in air. The temperature was controlled with K-type thermocouples with a $+/-2^{\circ} \mathrm{C}$ temperature accuracy along the gage length. Elastic and plastic deformations were measured with a high temperature contact extensometer. Some additional creep-fatigue experiments were performed under secondary vacuum $\left(5 \times 10^{-4} \mathrm{~Pa}\right)$ using the same mechanical and thermal conditions. The dwell-fatigue behavior of U720Li was compared to the low-cycle fatigue (LCF) and creep one at $700^{\circ} \mathrm{C}$. Experimental conditions of these tests are described elsewhere $[18,19]$.

\section{$\underline{\text { In-Situ SEM Tensile Tests }}$}

In-situ SEM tensile tests were performed on HS - Homogeneous samples. Experiments were performed with a DEBEN micromachine introduced in a Jeol 6100 SEM and with small flat micro tensile samples. Their gage length, width and thickness were $10 \mathrm{~mm}, 2 \mathrm{~mm}$ and $1 \mathrm{~mm}$, respectively. Samples were mechanically polished until obtaining a mirror finish (final polishing using a $1 \mu \mathrm{m}$ diamond spray). Additionally, their gage surfaces were electrochemically polished to remove any residual deformation or stress in the surface layers due to mechanical polishing. Electrochemical polishing was performed at $4{ }^{\circ} \mathrm{C}$ and under $45 \mathrm{~V}$ using a solution made of $10 \%$ perchloric acid in methanol. Since no extensometer can be used in our equipment during in-situ experiments, ex-situ tests were firstly performed with an extensometer fixed on the gage length to precisely establish the equivalent continuous stress-strain curve for this type of sample [20]. Experiments were performed at room temperature a very low strain rate of $8.0 \times 10^{-5} \mathrm{~s}^{-1}$. These conditions enabled tests to be stopped at a pre-determined stress or strain level, by stopping the motor, allowing the observation of several zones for the same level of elongation. Interruptions were performed every 200/300 MPa early in the elastic domain (up to $350 \mathrm{MPa}$ below conventional YS). Afterwards, interruptions were made every $15 / 20 \mathrm{MPa}$ to ensure a precise detection of the first events of plastic deformation. Finally, insitu tensile tests were stopped after a $0.01 \%$ and $0.36 \%$ plastic deformation for specimens $n^{\circ} 1$ and $n^{\circ} 2$ respectively, i.e. plastic deformation close to the ones that can be monitored/applied during representative LCF cycles or in the early stages of dwellfatigue loading.

\section{Microstructure Characterization}

The $\gamma / \gamma^{\prime}$ microstructures were characterized using the secondary electron mode of a JEOL 7000F SEM-FEG operating in the 20$25 \mathrm{kV}$ range. Microstructures were revealed after standard metallographic preparations and a chemical etching using a solution made of $1 / 3 \mathrm{HNO}_{3}+2 / 3 \mathrm{HCl}$ (vol. parts). Using such a solution, the $\gamma^{\prime}$ phase is dissolved and appears dark (see e.g. Figs 1d-f). Surface feature observations were performed using a Jeol 6400 SEM using either secondary or a back-scattered (BSE) mode. In-situ SEM tensile tests were performed in a Jeol 6100 SEM using the BSE mode. Grain size distributions and grain orientations were characterized by EBSD. The OIM software from EDAX was used both on the Jeol 6100 and Jeol 7000F SEM.

The cross-correlation approach, based on EBSD patterns, was used to compute the local strain/stress fields using the Cross Court CC3 software. Contrary to more conventional digital image correlation method, it does not require the deposition of particles on the sample's surface to allow the computation of local displacement [11]. This recently developed technique [2123] permits the evaluation of small crystalline lattice distortions and rotations from electron backscatter diffraction patterns obtained in a deformed crystalline material. For each grain of a polycrystal, all the patterns are compared to a reference one chosen in a non deformed zone of the grain. If the quality of the diffraction patterns is high enough, the distortions and rotations can be measured with a precision of $2 \times 10^{-4}$. The results of cross correlation calculations applied to the patterns obtained in a given scanned area is the distortion matrix $\mathrm{A}_{\mathrm{ij}}$ (Eq. (1)).

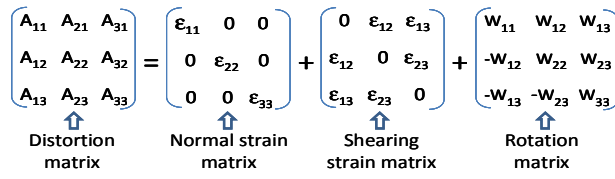

It is assumed that the measured distortions result from a combination of elastic strains and body rotations in the volume. From the distortion matrix $A_{i j}$, it is then possible to extract the components of strain tensor (normal strain $\varepsilon_{\mathrm{ii}}$ and shearing strain $\left.\varepsilon_{\mathrm{ij}}\right)$ and rigid body rotation $\left(\mathrm{W}_{\mathrm{ij}}\right)$ tensors. Having all the components of the strain tensor, it is then possible to determine the local elastic stress tensor using the elastic constants $\mathrm{Cij}$ of the alloy. Since elastic constants of Ni-based superalloys are quite independent on the alloy chemistry and nature (i.e. polycrystalline, DS or monocrystalline alloy) in the $20^{\circ} \mathrm{C}-$ $650^{\circ} \mathrm{C}$ temperature range [24], we used the elastic constants of In738LC for such calculations [24], an alloy with a very similar $\gamma$ ' volume content compared to U720Li.

\section{Macroscopic Mechanical Behavior And Damage Processes At $700^{\circ} \mathrm{C}$ Of Homogeneous And Heterogeneous Microstructures}

\section{$\underline{\text { Creep-Fatigue Interactions }}$}

The creep-fatigue behavior of both microstructures at $700^{\circ} \mathrm{C}$ is shown in Fig. 2a for a 10s dwell time at maximum applied stress. Compared to the Homogeneous structure, the Heterogeneous structure deforms faster and exhibits a higher pseudo-primary plastic strain. Moreover, it was observed that the Heterogeneous microstructure showed a greater ductility 
compared to the Homogeneous one; under the same maximum applied stresses $\sigma_{\max }$ (i.e. $750 \mathrm{MPa}$ and $800 \mathrm{MPa}$ ), the plastic strain at the transition between secondary and tertiary stages are greater than $1.5 \%$ for the Homogeneous structure compared to less than $0.5 \%$ for the Homogenous one. Such a difference in creep-fatigue behavior cannot be linked to the $0.2 \%$ YS. Their respective $\mathrm{YS}$ at $700^{\circ} \mathrm{C}$ under a $10^{-4} \mathrm{~s}^{-1}$ strain rate only differs of $10 \mathrm{MPa}[18,19]$. Surprisingly, such very pronounced differences in creep-fatigue behavior do not lead to any significant effect in creep-fatigue lives. Indeed, it is observed in Fig. 2a almost identical lives under $\sigma_{\max }=750$ and $\sigma_{\max }=800 \mathrm{MPa}$, despite very different plastic strains. Such a result allows us to compare the creep-fatigue behavior of both structures to their LCF one performed at $700^{\circ} \mathrm{C}\left(\mathrm{R}_{\sigma}=0.05\right.$, triangular waveform, $\left.\mathrm{f}=0.5 \mathrm{~Hz}\right)$ [18]. Under such conditions, it is observed that the introduction of a $10 \mathrm{~s}$ dwell time at maximum stress leads to a pronounced decrease of the fatigue life (Fig. 2b). The creep-fatigue life debit compared to LCF life is above one decade in the investigated stress range.

Elongation (\%)

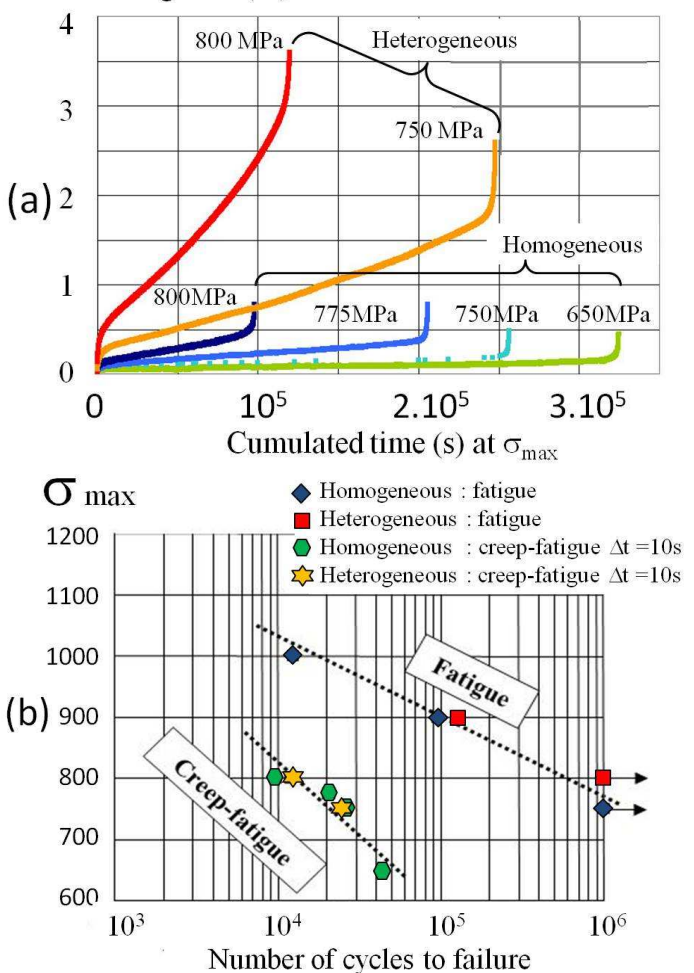

Figure 2. (a) Strain accumulation during dwell testing (dwell time $\Delta \mathrm{t}=10 \mathrm{~s}$ ); (b) Endurance data from creep-fatigue and fatigue testing at $700^{\circ} \mathrm{C}$ for both microstructures.

The results obtained under a dwell time at maximum stress $\Delta \mathrm{t}=$ $10 \mathrm{~s}$ were also confirmed for different $\Delta \mathrm{t}$, under $\sigma_{\max }=800 \mathrm{MPa}$. According to Fig. 3, it is observed that whatever the dwell time, Homogeneous and Heterogeneous structures have almost the same creep-fatigue life. Moreover, the fatigue life debit increases by increasing $\Delta \mathrm{t}$.

From the present macroscopic mechanical testing results, it appears that time dependent deformation processes have a huge contribution in the dwell-fatigue resistance of $\mathrm{U} 720 \mathrm{Li}$ at $700^{\circ} \mathrm{C}$ compared to its LCF resistance. Moreover, such processes lead to different macroscopic plastic strain rates as a function of the microstructure (i.e. Homogeneous vs Heterogeneous structure), probably due to a non-negligible contribution of grain boundary sliding to the macroscopic mechanical behavior [12]

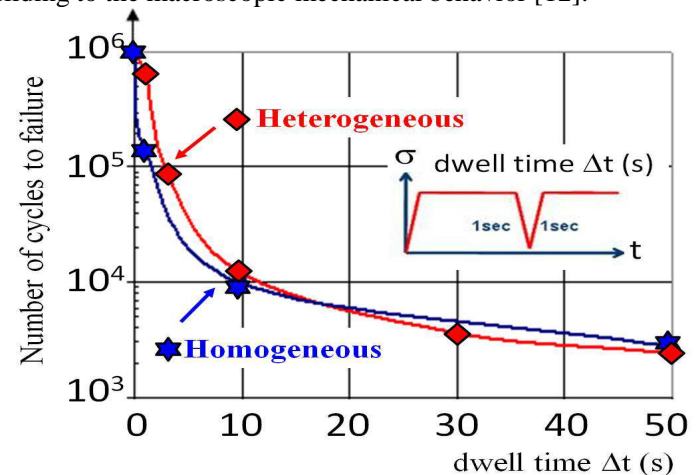

Figure 3. Creep-fatigue life at $700^{\circ} \mathrm{C}$ of the homogeneous and heterogeneous microstructures according to the dwell time for $\sigma_{\max }=800 \mathrm{MPa}$.

\section{Deformation And Damage Processes}

The analysis of deformation mechanisms in the early stages of creep-fatigue plastic deformation (i.e. up to $0.2 \%$ ) revealed a progressive transition from a dominant $\gamma^{\prime}$ shearing deformation mechanism to a dominant Orowan by-passing mechanism as the dwell time $\Delta \mathrm{t}$ at $\sigma_{\max }$ was increased [19]. The main difference between the Homogeneous and Heterogeneous structures is in this progressive transition from $\gamma^{\prime}$ shearing to by-passing at longer dwell times for the Heterogeneous microstructure [18]. We will not enter into deeper details about the deformation mechanisms since this aspect is somewhat out of the scope of the paper in the understanding of the contribution of grain boundaries to the mechanical behavior of U720Li. It is worth noticing however that a higher dislocations density was found using TEM near grain boundaries and that grain boundary sliding was also observed using scratches networks. This last observation is in good agreement with the nice experiments performed by A. Soula et al. under pure creep conditions [12, $25,26]$.

The crack initiation processes were investigated using creepfatigue experiments performed in air and under vacuum. It is observed in Fig. 4 that cracks always initiate from the free surface and exclusively at grain or twin boundaries, whatever the environmental conditions and hold time at $\sigma_{\max }$. It must be pointed out for the homogeneous microstructure with coarse grains that cracks initiated at the twins could be confused with slip lines due to their length and their straightness. Moreover, creep-fatigue lives were found to be longer under vacuum for the Heterogeneous microstructure by more than a factor 2 compared to testing in air. Testing under vacuum did not improve dwell-fatigue lives for the Homogeneous structure. Since crack initiation is surface-grain-boundary driven, the higher density of grain boundaries at the specimen's surface of the Heterogeneous structure is believed to be the origin of such a creep-fatigue life improvement under vacuum for this kind of microstructure. This could be easily understood from Figs. 4b 
and $4 \mathrm{~d}$ where it was observed that a higher density of surface micro-cracks were present within the clusters of small grains. Hence, the contribution of oxidation at grain boundaries is believed to enhance the kinetics of intergranular crack nucleation, without affecting the fundamental nature of the damage processes. This is in good agreement with previously published results using the same alloy under pure creep conditions at $850^{\circ} \mathrm{C}$ [27]

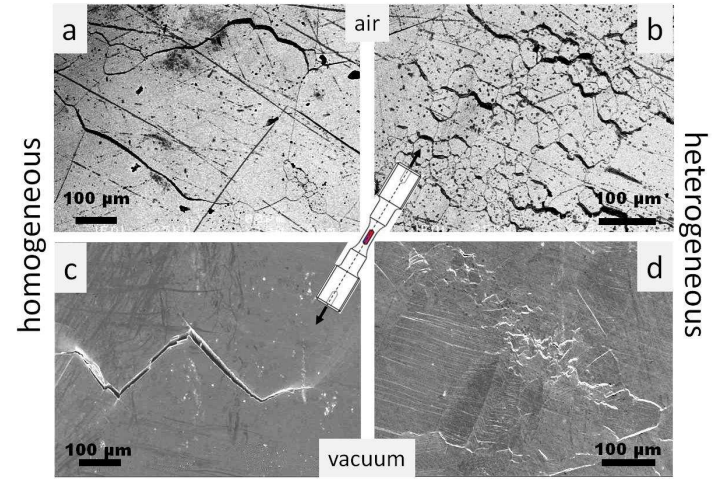

Figure 4. Intergranular and twin boundary crack initiation for Homogeneous $(\mathrm{a}, \mathrm{c})$ and Heterogeneous $(\mathrm{b}, \mathrm{d})$ structures, in air $(\mathrm{a}, \mathrm{b})$ and vacuum $(\mathrm{c}, \mathrm{d})$. Creep-fatigue testing conditions: $\sigma_{\max }=$ $800 \mathrm{MPa}$ and $\Delta \mathrm{t}=50 \mathrm{~s}$ in air/ $\Delta \mathrm{t}=10 \mathrm{~s}$ under vacuum.

\section{In-Situ SEM Tensile Tests At Room Temperature}

From the present conventional investigations of the creepfatigue behavior of $\mathrm{U} 720 \mathrm{Li}$ at $700^{\circ} \mathrm{C}$, it is understood that the durability of the alloy is controlled by the nucleation and development of (micro-)cracks at grain boundaries, whatever the environmental conditions and microstructures. Hence, understanding how the local grain configurations, the local crystallography, the nature of the grain boundary and the $\gamma^{\prime}$ precipitation control crack nucleation is fundamental to a better understanding of the alloy durability. In a first step toward such a better understanding, it is chosen to mainly focus on the contribution of the local crystallography (i.e. local Schmid factors, intragranular slip activity) and to simplify our testing conditions and microstructure configuration.

Therefore, deformation and damage processes at grain boundaries will be investigated using a combination of in-situ SEM tensile testing, conventional EBSD and cross-correlation measurements from EBSD patterns. These experiments will be performed at room temperature to avoid any contribution of time dependent deformation processes (e.g. dislocation recovery mechanisms) and using the HS-homogeneous microstructure (see Figs. 1c and 1f) which involves very limited strain hardening [17] and no $\gamma^{\prime}$ depleted layers near grain boundaries compared to both Homogeneous and Heterogeneous structures.

\section{$\underline{\text { Technical Details }}$}

Two in-situ SEM tensile tests (using specimen $\mathrm{n}^{\circ} 1$ and $\mathrm{n}^{\circ} 2$ ) were performed up to very limited plastic deformation. Specimens $n^{\circ} 1$ and $n^{\circ} 2$ were loaded step by step up to plastic strains of $0.01 \%$ and $0.36 \%$, respectively. 446 grains were monitored in the gage section of specimen $\mathrm{n}^{\circ} 1$ (Fig. 5a). First slip traces were observed at $805 \mathrm{MPa}$, i.e. $283 \mathrm{MPa}$ below the macroscopic $0.2 \%$ YS of the alloy [17]. Fig. 5b presents all the 55 grains along the gage length where slip traces could have been detected after the last stage of in-situ straining $(\sigma=900$ $\mathrm{MPa}, \varepsilon_{\mathrm{p}}=0.01 \%$ ). Note that twins were considered as grains in this representation. It was observed that plastically deformed grains are quite homogeneously distributed along the gage length, indicating unambiguously, under such a small plastic strain, that the bearing section is constant along the gage length.

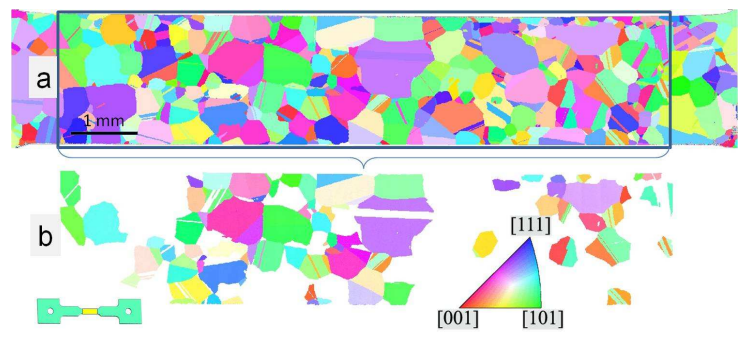

Figure 5. Inverse pole figure according to the loading direction of specimen $\mathrm{n}^{\circ} 1$ tested under monotonic tension in-situ in the SEM (a) and selection of the grains where slip traces have been observed at $\sigma=900 \mathrm{MPa}\left(\varepsilon_{\mathrm{p}} \approx 10^{-4}\right)(\mathrm{b})$.

From both the grain size and the local highest theoretical Schmid factor determined by EBSD, it is possible to determine whether plastic activity is controlled according to the grain size or to the Schmid law. It can be observed from Fig. 6 that the 55 grains where slip bands were identified are quite homogeneously distributed in grain size while their distribution is shifted to the highest Schmid factors. Hence, under such room temperature tensile tests, yielding is mainly controlled by the Schmid law rather than by the grain size.

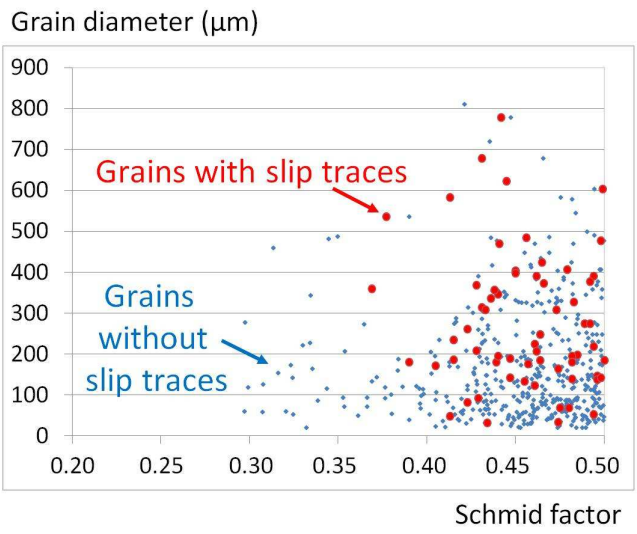

Figure 6. Grain size distribution as a function of their Schmid factor for the 446 grains investigated at the surface of specimen $\mathrm{n}^{\circ} 1$ during SEM in-situ straining for a stress level of $900 \mathrm{MPa}$ $\left(\varepsilon_{\mathrm{p}}=0.01 \%\right)$. Grain size determined from EBSD data. Large circles highlight 55 grains with slip traces; small circles correspond to grains without any slip activity (highest theoretical Schmid factor). 
Fig.7 gives examples of the first traces of slip bands detected at the 800,850 and $900 \mathrm{MPa}$ loading steps. Slip traces are straight and they generally directly interact with grain or twin boundaries at their two extremities. Note that the appearance of new slip traces could only be seen from one step to the next one. It is then not possible from this type of experiment to conclude on the kinetics of slip band activity. In particular the site of slip band emergence remains unidentified; it is unclear whether slip bands come from the bulk of the grains and rapidly progress to interact with boundaries or whether the process starts at boundaries. Moreover, the very low volume fraction of primary $\gamma^{\prime}$ precipitates that is present in this microstructure does not influence slip bands nucleation and propagation. For each case, the activated slip plane has been identified. The corresponding $\{111\}<110>$ system was considered, taking into account the highest calculated Schmid factor for the three coplanar systems. Note that a few twin boundaries also present a slip activity (Fig.7 d-e). In that case, the corresponding Schmid factor has been calculated as for conventional slip system considering the twin boundary plane as a slip plane.
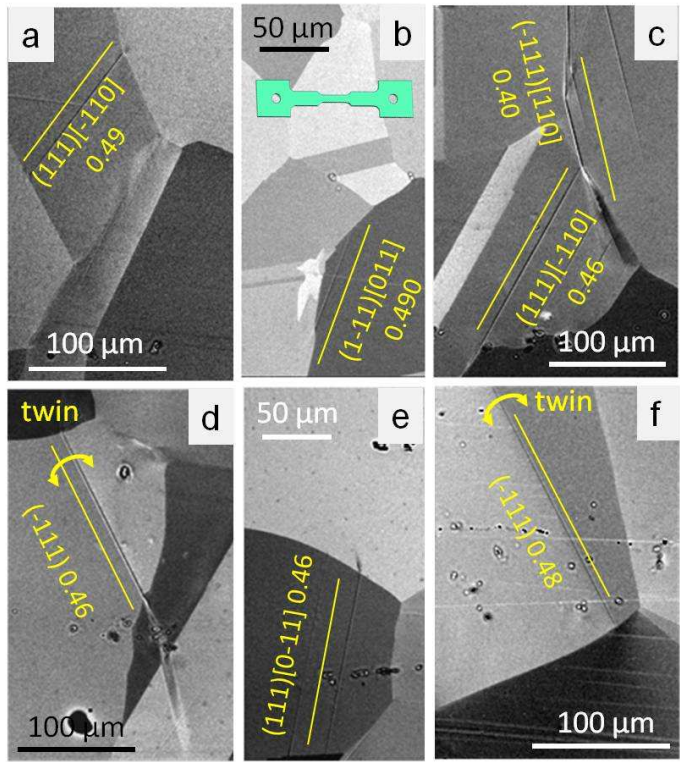

Figure 7. Deformation features of specimen $\mathrm{n}^{\circ} 1$ observed at different loading steps: $800 \mathrm{MPa}(\mathrm{a}, \mathrm{b}), 850 \mathrm{MPa}(\mathrm{c}, \mathrm{d})$ and 900 MPa (e,f). Identifications of slip planes and twins with their corresponding Schmid factors have been superimposed.

The surface of the sample was entirely investigated by SEM (BSE mode) under load (900 MPa). All the observed slip traces have been analyzed from EBSD data. The cumulated frequency of Schmid factor for all 446 grains is given in Fig. 8. It corresponds to the conventional distribution for a faced-cubiccentered material without any marked texture. For this type of distribution, about $90 \%$ of the grains have a Schmid factor higher than 0.41 , i.e. crystallographic configurations that essentially correspond to a single slip behavior. Similar curves have been plotted for grains that were found to develop slip bands only on the primary slip system or on more slip systems. They are nearly superimposed to the reference one. The distribution corresponding to slip on the twin boundary planes has been plotted too. Clearly those configurations correspond to a particularly high value of Schmid factor.

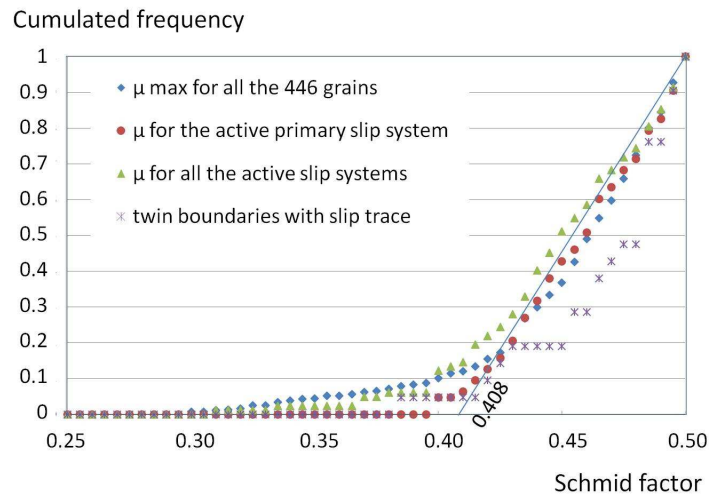

Figure 8. Cumulated frequencies of Schmid factors $\mu$ for all the grains studied during in-situ SEM tensile testing of specimen $\mathrm{n}^{\circ} 1$, for the active primary slip system of grains exhibiting slip, for all active primary slip systems and for twin boundaries with slip traces.

Conventional EBSD analyses were performed on the specimen $\mathrm{n}^{\circ} 2$ with a spatial resolution high enough (scans with steps of 50 to $200 \mathrm{~nm}$ ) to focus on the local crystalline orientation variations due to the heterogenous distribution of the plastic deformation introduced by the tensile test. This tensile test was stopped after $\varepsilon_{\mathrm{p}}=0.36 \%$. The investigated areas were chosen to consider different types of local grain boundary configurations. We paid special attention to the relative activity of slip bands that interact with neighboring grains across a grain boundary. The configurations mostly encountered present a high compatibility of slip systems that develop bands in the neighboring grains with an easy transmission of slip through the grain boundary. However, in a few number of cases, the crystalline orientation of both grains does not favor this easy slip band from one grain to the other. An example of such a configuration is given by Fig. 9 for the specimen $n^{\circ} 2$. This case corresponds to a particularly unfavorable configuration since the grain at the right bottom of the area is oriented according to the loading axis to favor the D1 (1-11)[011] system with a very high Schmid factor $\mu=0.497$. In contrast, the grain on the top left is oriented near the [111] direction that clearly less favors slip activity in the D1 (111)[011] systems $(\mu=0.292)$. As it can be seen in Fig. 9, very small volumes that present specific deformation features develop in the less deformed grain directly in front of the slip bands that interact with the grain boundary in the more deformed grain These specific areas correspond to pronounced micro-crystalline rotations well illustrated by the plot of a grain reference orientation deviation map (Fig. 9b). In such a figure, each point is shaded according to its angular deviation to a reference orientation for the grain to which it belongs. In that case, the reference orientation is the average orientation for the grain. The conventional use of EBSD allows local misorientation profiles through these micro-volumes to be quantified with an angular accuracy of about 0.5 degrees. The disorientation measured in such zones reached 12 degrees in the more pronounced cases. 

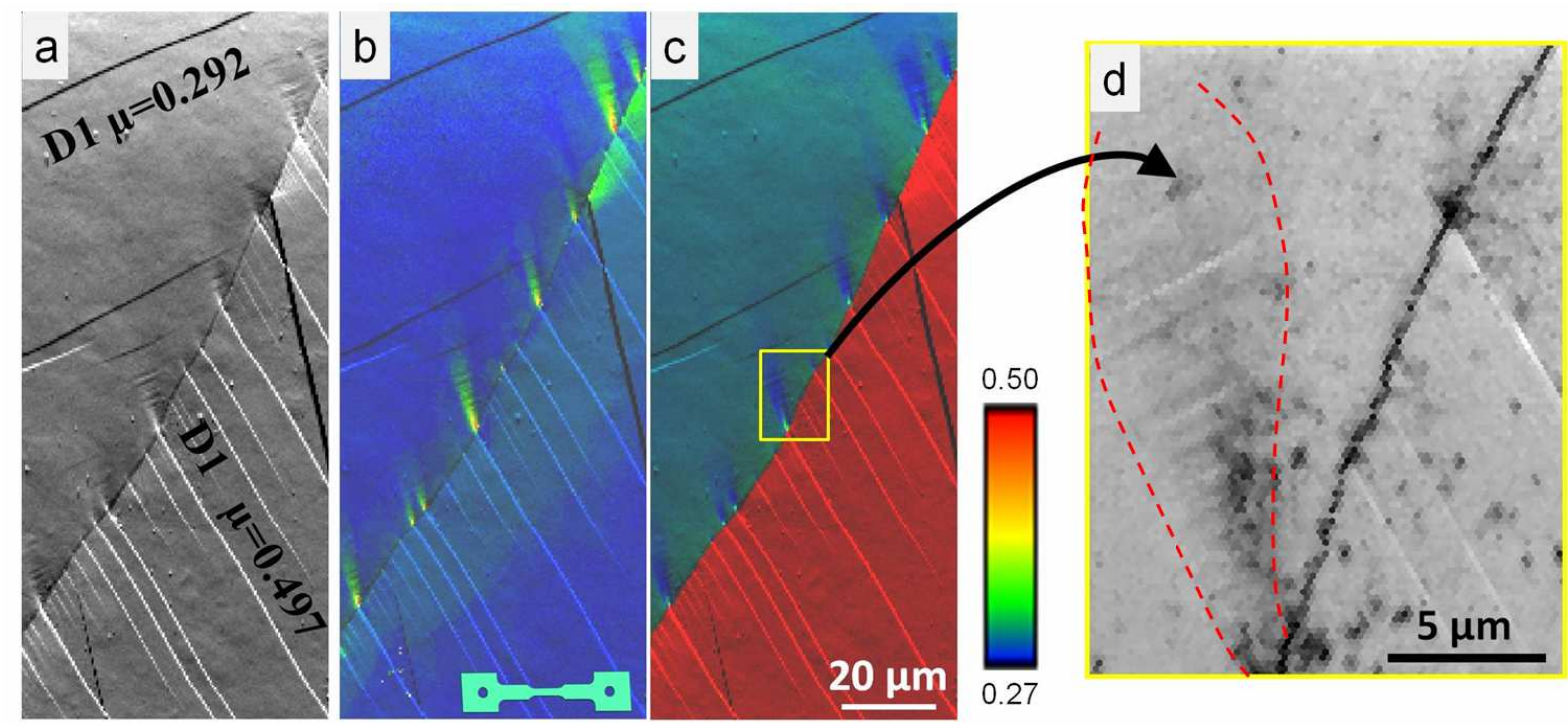

Figure 9. EBSD investigation of slip band interactions with grain boundaries in specimen $\mathrm{n}^{\circ} 2$ : Backscattered electron image (BSE) with slip systems and corresponding Schmid factor (a); BSE + grain reference orientation deviation image (b); BSE + Schmid factor and corresponding color scale levels (c); area where cross correlation measurements have been performed (d). Note that the area with localized intense plasticity in which slip bands are activated is defined by dotted curves in (d).

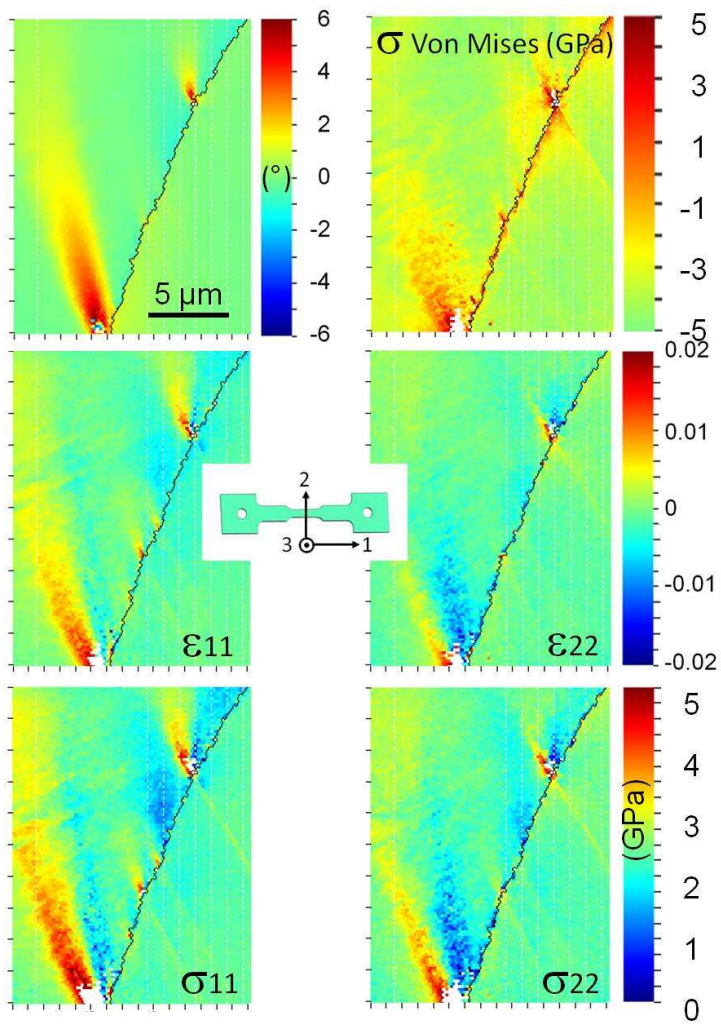

Figure 10. Rotation, stress and strain maps calculated using the cross correlation approach. $\mathrm{W}_{31}$ is the micro-rotation around the 2 axis; $\varepsilon_{11}, \varepsilon_{22}, \sigma_{11}$ and $\sigma_{22}$ are the normal strains and stresses according to the 1 and 2 directions respectively.
The cross correlation (CC) method was used to investigate these local processes, not only because of the better accuracy for rotation measurements but mainly to establish local strain stress maps. Fig. 9d gives the backscattered image corresponding to a small scan $\left(15 \times 20 \mu \mathrm{m}^{2}\right)$ performed with a step of $200 \mathrm{~nm}$ for $\mathrm{CC}$ analysis. It must be mentioned that such analysis is much more time consuming than conventional EBSD since each Kikuchi diffraction pattern must be acquired with a high level of brightness and contrast to allow the mathematical correlation of images from two neighboring patterns. These conditions require the time of exposure to be increased by a factor of at least 200. The post-processing of the data needs to define a reference pixel for each grain. These points were chosen far enough from the grain boundary and between slip bands to ensure a particularly low level of deformation. The results of the cross correlation is firstly the quantitative determination of the components of the distortion matrix $\mathrm{A}_{\mathrm{ij}}$ (Eq.(1)). The next step is to extract the components of the rigid body $\left(\mathrm{W}_{\mathrm{ij}}\right)$ and strain (normal $\left(\varepsilon_{\mathrm{ii}}\right)$ and shearing $\left.\left(\varepsilon_{\mathrm{ij}}\right)\right)$ tensors. As an example, the Fig. 10 presents the $\mathrm{W}_{31}, \varepsilon_{11}$ and $\varepsilon_{22}$ corresponding maps. The crystalline rotation within the very small volumes involved in the interactions with the slip bands operating in the neighboring grain are mapped with an accuracy of about 0.01 degree. In the example this rotation reaches 6 degrees. The area concerned by these three dimensional rotations penetrates deep into the [111] grain, progressively enlarges and decreases in rotation amplitude. Due to the crystalline rotation within this volume, the mechanical local conditions according to the macroscopic loading direction are modified. The Schmid factor of the most favorably oriented slip system increases up to 0.37 near the grain boundary instead of 0.29 in the "bulk" far from the grain boundary. The consequence is the appearance of short segments of slip bands within the rotated volume as it can be seen in Fig. 9d. In the central part of the micro-volumes involved in crystalline rotations, the elastic strain reaches $2 \%$. From the components of the strain tensor, the local elastic stress tensor 
was calculated. The maps corresponding to the $\sigma_{11}$ and $\sigma_{22}$ components are given in the Fig.10 with the von Mises stresses too. Highly localized residual elastic tensile and compressive stresses are evaluated by this method within these small volumes. Even if interpretation of these stress magnitudes remains quite difficult, these local mechanical configurations are very likely to favor crack initiation especially in the case of cyclic loading. It must be mentioned that such local microvolumes that show crystalline rotations have also been observed for different grain boundary configurations in the specimen $\mathrm{n}^{\circ} 1$ for which the macroscopic strain reached was only $\varepsilon_{\mathrm{p}} \approx 0.01 \%$, a value of strain amplitude which is typically found in low cycle fatigue. For both samples, a lot of local configurations are observed for which slip bands were found to develop in neighboring grains, with evidence that slip bands were transmitted across grain boundaries. Micro-scaled volumes with crystalline rotations were never detected in these cases.

Another point concerns the initiation and development of slip bands into the grain in interaction with these micro-volumes of lattice rotation. It has been shown that a few segments of slip bands are formed within the micro-volumes due to the progressive local re-orientation of the lattice (Fig. 9d). In a lot of cases, we have observed the development into the grain of long slip bands out of these micro-volumes on well oriented slip systems (high Schmid factor) generally different than the one active inside the micro-volumes. This transition is promoted by the high level of residual stresses produced within the microvolumes (Fig. 10). Fig. 11 illustrates a local configuration with two micro-volumes developed from two opposite grain boundaries in the same grain. This configuration leads to the initiation of a crack even if the macroscopic strain remains very limited $\left(\varepsilon_{\mathrm{p}} \approx 0.01 \%\right)$. Note that this configuration was the only one detected on the whole investigated surface. In this case, it is proposed that the local stress state is complex, and has led to cracking in the central part of the grain, which is partially not consistent with the slip band activity $((-111) \mu=0.44)$.
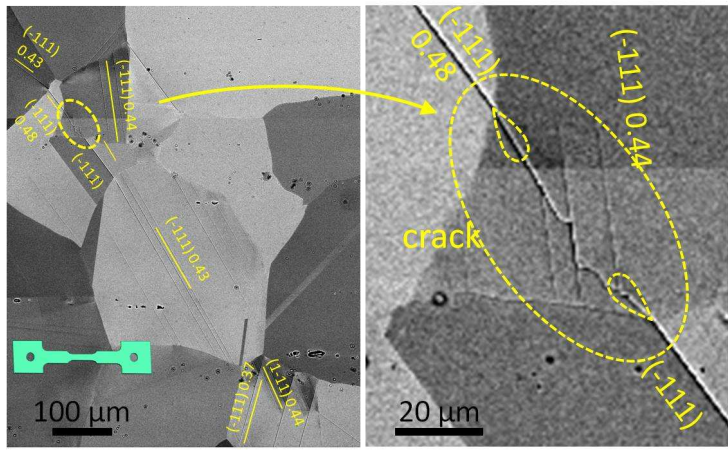

Figure 11. Specimen $\mathrm{n}^{\circ} 1 \quad\left(\varepsilon_{\mathrm{p}}=0.01 \%\right)$. Alignment of grains where a few slip bands have been detected and corresponding high magnification image of a grain for which the development of micro-volumes (in dashed lines) have interacted with slip bands in the (-111) planes to develop a crack.

\section{Discussion}

This paper points out complex processes of crystalline rotation combined with plasticity activity that lead to a high level of local stresses in micro-volumes $\left(\approx \mathrm{a}\right.$ few $\left.\mu \mathrm{m}^{3}\right)$ localized at grain boundaries. Such volumes develop themselves in one side of the boundary directly in relation with slip bands activated in the neighboring grain. To our best knowledge, these phenomena have never been mentioned in the open literature.

We feel that they are really important when considering the durability of such a structural material under low cycle fatigue or creep-fatigue loading. Indeed, they were revealed for very low plastic strains (as low as $0.01 \%$ ) in the macroscopic elastic domain, i.e. loading amplitudes compatible with the ones that can be encountered for cyclic excursions in structural components. Then, a question that should be addressed concerns the evolution of such micro-volumes when the strain amplitude increases, for monotonic as well as for cyclic loading. It is expected that an increase in the (macroscopic) plastic strain should increase both the spatial extent of such micro-volumes and the local lattice rotation amplitude in it. Such an evolution could favor crack initiation at grain boundaries (see e.g. Fig. 11) For higher plastic strain amplitudes, small cracks are initiated directly in grain boundaries, especially when intense slip activity is developed in both neighboring grains, as it is illustrated by Fig.12.

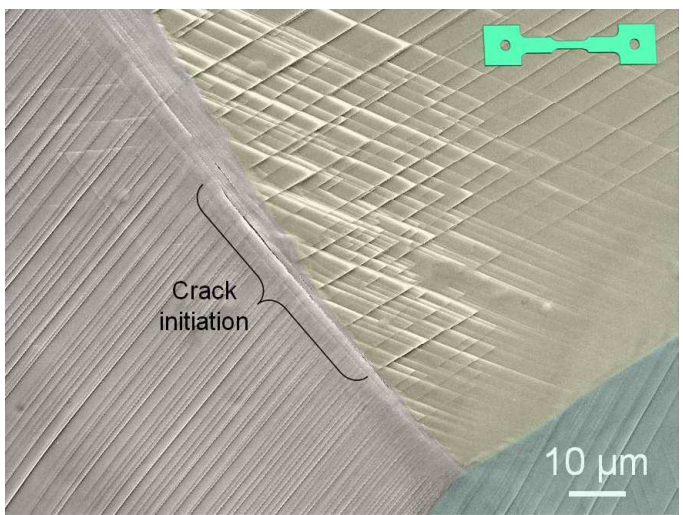

Figure 12. Example of crack initiation at grain boundary at room temperature due to slip band activity in the grains (In-situ SEM tensile test, $\varepsilon_{\mathrm{p}} \approx 2.5 \%$ ).

From the present investigation, we have demonstrated that these micro-volumes develop if a sufficiently large difference in Schmid factors exists between the two crystalline domains separated by the grain boundary. The development of these micro-volumes is also highly dependent on the number of active slip systems in each grain and on the way by which slip interacts with the grain boundary. These crystallographic aspects will be considered and analyzed in detail in a forthcoming paper [28].

Finally, it seems evident that the nucleation and development of these micro-volumes is highly "microstructure" sensitive, i.e. the underlying $\gamma^{\prime}$ precipitation may control the extent of these volumes. As an example, secondary $\gamma^{\prime}$-particles depleted layers close to grain boundaries in the Homogeneous and Heterogeneous structures (not shown in this article) are likely to modify the extent and local stress intensity in these microvolumes. Work is in progress to better understand the role of the $\gamma^{\prime}$ precipitation (especially its size and morphology) and of the viscoplasticity in the nucleation and growth of these micro- 
volumes. The way by which micro-cracks initiate from these volumes as observed in Fig. 11 is the next step that must be studied. One possible way in getting such a better understanding in the transition from local intense plasticity to micro-cracking at such small scales is to combine the use of high-temperature insitu SEM tensile/LCF testing [10], EBSD pattern crosscorrelation and subsequent three-dimensional reconstructions of the local considered volumes using a FIB slice and view technique [29] or an in-situ SEM laser ablation technique [30].

For the future, a better understanding of the damage processes from these micro-volumes could be essential to propose more resistant metallurgical microstructures near grain boundaries that would be obtained by specific thermo-mechanical treatments.

\section{Conclusions}

The contribution of grain boundaries to the creep-fatigue behavior and damage processes at $700^{\circ} \mathrm{C}$ of Udimet ${ }^{\circledR} 720 \mathrm{Li}$ has been investigated as a function of its microstructure. It is shown that whatever the microstructure (i.e. coarse homogeneous grain structure or heterogeneous duplex grain structure with clusters of small grains merged in a coarse grains skeleton) and whatever the environmental conditions (i.e. in air or under vacuum), crack initiation and first stages propagation are intergranular. Microstructure differences in grain sizes and distributions were only found to affect the creep-fatigue behavior: heterogeneous grained structures creep faster and allow a greater ductility before transition to a tertiary stage.

To improve our understanding of the exact role of grain boundaries and to identify critical crystalline configurations leading to possible cracks nucleation, in-situ SEM tensile tests were performed up to very small plastic strains $(0.36 \%$ at maximum). These experiments were performed at room temperature to avoid the contribution of time-dependent processes. A "model" microstructure with a homogeneous coarse grain structure and an intragranular $\gamma^{\prime}$ precipitation inducing little strain hardening was used for the specific purpose of these experiments. The use of the EBSD patterns crosscorrelation technique allowed measuring the local strain-stress fields close to grain boundaries. It was observed that first traces of slip activity are mainly Schmid factor driven and not grain size driven. Moreover, it was found that near grain boundaries separating crystalline domains that have a plastic activity contrast (e.g. one grain with slip activity and its adjacent without slip), the development of small volumes $\left(\sim 1-2 \mu \mathrm{m}^{3}\right)$ have been detected ahead of slip traces where very intense plastic activity and large rotations are measured. Local stresses of several GPa were measured in these volumes. Such volumes are believed to be highly sensitive to the local $\gamma^{\prime}$ microstructure and to the grain boundary geometrical configuration and nature. Considering the measured stress magnitudes, it is expected that under cyclic loadings, such a localized plasticity is critical in nucleating small cracks at grain boundaries.

\section{Acknowledgements}

Part of the present investigation has been conducted within the ANR project "ORGANDI". The authors would like to thank the CNRS (Centre National de la Recherche Scientifique) and Région Poitou - Charentes for the grant of Thomas Billot Ph.D. Thesis). Turbomeca - SAFRAN group is gratefully acknowledged for providing the materials and for collaboration with Institut Pprime over a decade on Ni-based superalloys activities.

Alexandre Devaux and Christian Dumont (Aubert \& Duval, Les Ancizes) are also gratefully acknowledged for their continuous interest in this study and for providing material for SEM in-situ testing.

\section{References}

1. M. Mazière et al., "Overspeed burst of elastoviscoplastic rotating disks - Part I: Analytical and numerical stability analyses", European Journal of Mechanics A/Solids, 28 (2009), 36-44.

2. R.C. Reed, The Superalloys - Fundamentals and Applications (Cambridge, UK: Cambridge University Press, 2006).

3. F.E. Sczerzenie and G.E. Maurer. "Development of Udimet 720 for high strength disk applications", Superalloys 1980, ed. J.K. Tien, S.T. Woldek, H. Morrow III, M. Gell and G.E. Maurer, (Warrendale, PA: The Mineral, Metals and Materials Society, 1980), 573-580.

4. D. Helm and O. Roder. "Influence of long term exposure in air on microstructure, surface stability and mechanical properties of Udimet 720Li", Superalloys 2000, ed. T.M. Pollock, R.D. Kissinger, R.R. Bowman, K.A. Green, M. McLean, S. Olson and J.J. Schirra, (Warrendale, PA: The Mineral, Metals and Materials Society, 2000), 487-493.

5. S.K. Jain, B.A. Ewing, and C.A. Yin. "The development of improved performance PM UDIMET 720 Turbine disks", Superalloys 2000, ed. T.M. Pollock, R.D. Kissinger, R.R. Bowman, K.A. Green, M. McLean, S. Olson and J.J. Schirra, (Warrendale, PA: The Mineral, Metals and Materials Society, 2000), 785-794.

6. K. Steffens and H. Wilhelm, "Next engine generation: Materials, Surface Technology, Manufacturing processes. What comes after 2000?" http://www.mtu.delen/technologies/engineering_news/productio n/Steffens_Next_engine_generation.pdf.

7. D.U. Furrer, R. Shankar, and C. White, "Optimizing the Heat Treatment of Ni-Based Superalloy Turbine Discs", JOM, 55 (March) (2003), 32-34.

8. J. Mao et al., "An Investigation on Quench Cracking Behavior of Superalloy Udimet 720LI Using a Fracture Mechanics Approach", Journal of Materials Engineering and Performance, 9 (2000), 204-214.

9. J. Miao, T.M. Pollock, and J.W. Jones, "Microstructural Extremes and the Transition from Fatigue Crack Initiation to Small Crack Growth in a Polycrystalline Nickel-base Superalloy", Acta Materialia, 60 (2012), 28402854. 
10. X. Huang et al., "Experimental Investigation on Microcrack Initiation Process in Nickel-Based Superalloy DAGH4169", International Journal of Fatigue, 42 (2012), 153164.

11. M.A. Tschopp et al., "Microstructure-dependent local strain behavior in polycrystals through In-Situ scanning electron microscope tensile experiments", Metallurgical and Materials Transactions, 40A (10) (2009), 2363-2368.

12. A. Soula et al. "Grain Boundary and Intragranular Deformations during High Temperature Creep of a PM NickelBased Superalloy", Superalloys 2008, ed. R.C. Reed, K.A. Green, P. Caron, T.P. Gabb, M.G. Fahrmann, E.S. Huron and S.A. Woodard, (Warrendale, PA: The Mineral, Metals and Materials Society, 2008), 387-394.

13. P.S. Karamched and A.J. Wilkinson, "High resolution electron back-scatter diffraction analysis of thermally and mechanically induced strains near carbide inclusions in a superalloy", Acta Materialia, 59 (1) (2011), 263-272.

14. D.U. Furrer and H.-J. Fecht, " $\gamma$ ' formation in superalloy U720Li", Scripta Materialia, 40 (11) (1999), 12151220.

15. J. Mao et al., "Cooling precipitation and strengthening study in Powder Metallurgy Superalloy U720Li", Metallurgical and Materials Transactions, 32A (2001), 2441-2452.

16. R. Radis et al., "Multimodal size distribution of $\gamma^{\prime}$ precipitates during continuous cooling of UDIMET $720 \mathrm{Li}^{\prime}$, Acta Materialia, 57 (2009), 5739-5747.

17. J.R. Vaunois et al. "Influence of both $\gamma^{\prime}$ distribution and grain size on the tensile properties of UDIMET 720Li at room temperature", $7^{\text {th }}$ International Symposium on Superalloys 718 and Derivatives, ed. E.A. Ott, J.R. Groh, A. Banik, I. Dempster, T.P. Gabb, R. Helmink, X. Liu, A. Mitchell, G. Sjöberg and A. Wusatowska-Sarnek (Pittsburgh, PA: The Mineral, Metals and Materials Society, 2010), 199-213.

18. T. Billot, "Comportement et endommagement en fatigue et fatigue-fluage à haute température de différents états microstructuraux du superalliage base-nickel Udimet 720", (Ph.D. thesis, ENSMA, 2010).

19. T. Billot et al., "Creep Fatigue behavior at high temperature of a UDIMET 720 nickel-base superalloy", International Journal of Fatigue, 32 (5) (2009), 824-829.

20. F. Bridier, P. Villechaise, and J. Mendez, "Analysis of the different slip systems activated by tension in a $\alpha / \beta$ titanium alloy in relation with local crystallographic orientation", Acta Materialia, 53 (2005), 555-567.

21. A.J. Wilkinson, G. Meaden, and D.J. Dingley, "Highresolution elastic strain measurement from electron backscatter diffraction patterns: New levels of sensitivity", Ultramicroscopy, 106 (2006), 307-313.
22. G. Miyamoto et al., "Precise measurement of strain accommodation in austenite matrix surrounding martensite in ferrous alloys by electron backscatter diffraction analysis", Acta Materialia, 57 (2009), 1120-1131.

23. A.J. Wilkinson, G. Meaden, and D.J. Dingley, "Mapping strains at the nanoscale using electron back scatter diffraction", Superlattices and Microstructures, 45 (2009), 285294.

24. W. Hermann et al. "Elastic properties and determination of elastic constants of nickel-base superalloys y a free-free beam technique", Superalloys 1996, ed. R.D Kissinger, D.J. Deye, D.L. Anton, A.D. Cetel, M.V. Nathal, T.M. Pollock and D.A. Woodford, (Warrendale, PA: The Mineral, Metals and Materials Society, 1996) 229-238.

25. A. Soula et al., "Analysis of high temperature creep deformation in a polycristalline nickel-based superalloy", Materials Science and Engineering A, 510-511 (2009), 301-306.

26. A. Soula et al., "Quantitative evaluation of high temperature deformation mechanisms: a specific microgrid extensometry technique coupled with EBSD analysis", Journal of Materials Science, 45 (2010), 5649-5659.

27. E. Chateau and L. Remy, "Oxidation - assisted creep damage in wrought nickel-based superalloy: experiments and modelling", Materials Science and Engineering A, 527 (7-8) (2010), 1655-1664.

28. P. Villechaise and J. Cormier, "Influence of the local crystallography on the nucleation and development of intense localized plasticity at grain boudaries in a forged Ni-based superalloy", To be published, (2012).

29. M. Jouiad et al., "3D imaging using X-Ray tomography and SEM combined FIB to study non isothermal creep damage of (111) oriented samples of $\gamma / \gamma^{\prime}$ nickel base single crystal superalloy MC2", Materials Science Forum, 706-709 (2012), 2400-2405.

30. M.P. Echlin et al., "A new TriBeam system for threedimensional multimodal materials analysis", Review of Scientific Instruments, 83 (2012), 023701 